\title{
Termografia de feridas experimentais tratadas ou não com membrana amniótica
}

Fernanda Bovino;, Matheus de Oliveira Souza Castro, Rafaela Speranza Baptista, Natalia Machado Rahal, Camila Sabino de Oliveira, Daniela Scantamburlo Denadai, Francisco Leydson Formiga Feitosa, Luiz Claudio Nogueira Mendes, Flavia de Almeida Lucas

Faculdade de Ciências Agrárias de Andradina (FCAA), Fundação Educacional de Andradina (FEA), Andradina, SP, Brasil

*Autor correspondente

e-mail: ferbovino@yahoo.com.br

\section{Resumo}

O objetivo do estudo foi avaliar e comparar termograficamente a cicatrização de feridas experimentais nos membros torácicos e pélvicos de ovinos, tratados ou não com Membrana Amniótica (MA). Foram utilizadas 12 ovelhas Suffolk, adultas e hígidas, divididas aleatoriamente em dois grupos de seis, um com feridas realizadas nos membros torácicos (MT) e outro no membro pélvico (MP). Em cada grupo, as feridas foram confeccionadas e receberam o tratamento ( $\mathrm{T}$ ) no membro direito ou esquerdo, aleatoriamente, sendo o contralateral usado como controle (C). 0 mesmo esquema foi utilizado nos membros pélvicos. Após sedação com cloridrato de xilazina a $2 \%(0,1 \mathrm{mg} / \mathrm{kg}$ IM) e bloqueio local infiltrativo com cloridrato de lidocaína a $2 \%$ sem vasoconstritor no local a ser excisado, as feridas foram confeccionadas com o auxílio de um molde quadrangular com $1 \mathrm{~cm}$ de lado para a remoção do fragmento de pele. Todas as feridas foram tratadas com solução fisiológica a 0,9\% e enfaixadas com ataduras de crepe, em dias alternados, até completa cicatrização. A imagem termográfica foi realizada antes da confecção da ferida $\left(\mathrm{D}_{0 \mathrm{~A}}\right)$, logo após $\left(\mathrm{D}_{0}\right)$ e após três, sete e 15 dias $\left(D_{3}, D_{7}\right.$ e $\left.D_{15}\right)$. A termografia foi feita sempre no mesmo horário, com uso da câmara Flir i60 em tempo real, com distância padrão de $1 \mathrm{~m}$ da pele íntegra. As imagens foram analisadas pelo programa Flir Tools, avaliando a temperatura da área da ferida durante o processo cicatricial. Os dados foram submetidos à análise de variância com dois fatores com medidas repetidas no tempo, considerando o animal como bloco. As médias foram comparadas pelo teste de Tukey, considerando significativo $\mathrm{P}<0,05$. Entre os momentos, observou-se nos MTs que os dois momentos iniciais $\left(D_{0 A}\right.$ e $\left.D_{0}\right)$ diferem do $D_{3}$ e do $D_{7}$, sendo que, no sétimo dia de avaliação, foram encontradas as maiores médias de temperatura. No MP (C) há somente diferença entre a primeira aferição $\left(\mathrm{D}_{0 \mathrm{~A}}\right)$ com o $\mathrm{D}_{7}$, e no $\mathrm{MP}(\mathrm{T})$ a diferença está no D0A com D15, sendo sempre as temperaturas inicias menores que as finais. Quando comparados os tratamentos, não observou-se diferença. Entretanto, na comparação entre membros, denota-se em $\mathrm{D}_{0}$ que MT (T) é diferente do MP (T) e que o MT (C) difere 
do MP (C), e que em $D_{15}$, MT (C) é diferente do MP(C), sendo sempre as maiores temperaturas encontradas nos membros pélvicos. As feridas nos membros de ovinos apresentam temperatura levemente maior nos MPs. Os maiores valores de temperatura são observados em $D_{7}$, momento este em que provavelmente as feridas apresentaram maior fluxo sanguíneo cutâneo, decorrentes do processo inflamatório. Sendo assim, nas condições experimentais deste estudo, pode-se concluir que durante o processo cicatricial não houve diferenças de temperatura nas feridas tratadas ou não. 